\title{
O ensino-aprendizagem da entrevista de emprego em língua inglesa em curso técnico de nível médio
}

\begin{abstract}
Geraldo Máximo da Silva* Samuel de Carvalho Lima**

Resumo

O objetivo deste artigo é relatar uma experiência de ensino-aprendizagem do gênero oral entrevista de emprego em língua inglesa, com foco na pronúncia inteligível, considerando o contexto de turmas numerosas da escola pública. Metodologicamente, desenvolvemos uma intervenção pedagógica no Curso Técnico de Nível Médio em Informática do Instituto Federal do Rio Grande do Norte, campus Mossoró, através de uma proposta de ensino de 30h/a cujas atividades foram realizadas em duplas e em grupos. Nossa experiência se demonstrou produtiva tanto por ter contado com a participação de todos os alunos quanto por ter oportunizado o aumento de sua proficiência. Concluímos que nossa proposta de ensinoaprendizagem é flexível para outros contextos de oferta pública e gratuita da Educação Básica, devendo ser adaptada em função dos documentos norteadores e da promoção do ensino de língua inglesa.

Palavras-chave: ensino-aprendizagem, entrevista de emprego, língua inglesa, curso técnico.
\end{abstract}

The teaching-learning of job interview in english at high school technical course

Abstract

The aim of this article is to report a teaching-learning experience of the oral genre job interview in English, focusing on intelligible pronunciation, considering the context of large classes of public school. Methodologically, we developed a pedagogical intervention in High School Integrated Technical Course in Computersat Instituto Federal do Rio Grande do Norte, campus Mossoró, through a 30-class-hours teaching proposal in which the activities were carried out in pairs and in groups. Our experience proved to be productive both for having counted on the participation of all the students and for having opportunized the increase of their proficiency. We conclude that our teaching-learning proposal is flexible for other contexts of free and public offer of Basic Education, and it should be adapted according to the guiding documents and the promotion of English teaching.

Keywords: teaching-learning, job interview, English, technical course.

\section{Considerações Iniciais}

O ensino de língua inglesa na escola pública sempre foi alvo de críticas. Muitos questionam seu verdadeiro objetivo, pois não parece oportunizar verdadeiramente o desenvolvimento de competências comunicativas. A memorização de vocabulário e de estruturas gramaticais, sobretudo do verbo to be, perpassa o imaginário do que se é

\footnotetext{
* Professor de inglês do Instituto Federal do Rio Grande do Norte, campus Mossoró. E-mail: geraldo.maximo@ifrn.edu.br.

** Professor de inglês do Instituto Federal do Rio Grande do Norte (IFRN), campus Mossoró. E-mail: samuel.lima@ifrn.edu.br.
} 
aprendido e ensinado ao longo dos anos de contato com o inglês na Educação Básica. Embora tenhamos atravessado décadas de grandiosos avanços tecnológicos nas áreas de comunicação e de didática das línguas, porém, o ensino de línguas estrangeiras na sala de aula regular da escola pública parece haver permanecido quase intocado por esses avanços.

No âmbito da Educação Profissional e Tecnológica (EPT), quanto à oferta de ensino de inglês no Instituto Federal de Educação, Ciência e Tecnologia do Rio Grande do Norte, campus Mossoró (IFRN), tem-se clara a orientação para o ensino comunicativo da língua. Essa sugestão é apresentada nas Propostas de Trabalho das Disciplinas do Ensino Médio (PTDEM), resultante do engajamento coletivo entre professores e equipe técnico-pedagógica, apoiados nos documentos norteadores para o ensino na Educação Básica.

No entanto, adotar uma abordagem comunicativa no ensino de língua inglesa em uma sala de aula regular implica, sem dúvidas, além de superar as dificuldades no próprio plano metodológico, vencer também os obstáculos postos pelo ambiente físico em si, para conseguir promover as situações de comunicação e, em especial, a comunicação oral, tendo em vista as demandas de uma abordagem comunicativa de ensino em um contexto de turma numerosa (RICHARDS; RODGERS, 1999; ALMEIDA FILHO, 2001; LOO, 2007; SHAMIM et al., 2007).

Partindo desse contexto, desenvolvemos uma proposta de ensino-aprendizagem do gênero oral entrevista de emprego em língua inglesa no Curso Técnico de Nível Médio em Informática IFRN, com foco, sobretudo, na pronúncia inteligível dos nossos alunos (cf. SILVA, 2018). O objetivo deste artigo é relatar essa experiência de intervenção pedagógica realizada no último bimestre letivo de 2017, consolidando-se em 10 encontros que totalizaram 30h/a.

O gênero entrevista de emprego é constitutivo da nossa proposta de ensinoaprendizagem por integrar os objetivos e os conteúdos previstos no programa da disciplina de língua inglesa e, ao mesmo tempo, constituir-se um gênero oral pertinente às necessidades dos alunos do curso técnico de nível médio e suas relações com o mundo do trabalho.

Para além destas considerações iniciais, nosso artigo está dividido em mais 4 seções. A seguir, em nossa seção de escolhas teóricas, resenhamos aspectos do ensino 
comunicativo de inglês em turmas numerosas. Posteriormente, na seção do contexto da intervenção pedagógica, descrevemos a proposta de ensino-aprendizagem da entrevista de emprego em inglês elaborada para curso técnico de nível médio. Na seção de relato da experiência, narramos os 10 encontros e citamos as atividades praticadas em sala de aula. Por fim, em nossas considerações finais, elucidamos as implicações pedagógicas do nosso estudo, bem como apontamos algumas limitações do nosso escopo e possíveis continuidades de pesquisa em ensino de inglês na escola pública.

\section{Escolhas teóricas}

O desenvolvimento da competência comunicativa em uma língua estrangeira tem sido um desafio para o contexto de ensino-aprendizagem da Educação Básica pública e gratuita. Leffa (1988) afirma que o uso da linguagem apropriada, adequada à situação em que ocorre o ato da fala e ao papel desempenhado pelos participantes, é uma grande preocupação da abordagem comunicativa. $\mathrm{O}$ autor reforça ainda que a ênfase da aprendizagem está, de fato, na comunicação e não em diálogos elaborados meramente para apresentar pontos gramaticais. Essa afirmação se traduz na condição de fazer um uso autêntico da língua estudada, empregando-a nos diversos contextos além da sala de aula, nos quais os aprendizes podem se deparar com as mais variadas situações, que requerem deles conhecimento e independência para agirem.

Tendo como objetivo o desenvolvimento da competência comunicativa, a abordagem comunicativa tem na oralidade uma das principais ferramentas para envolver o aluno em situações reais de interação, buscando proporcionar ao aprendiz a autonomia linguística. E sendo a oralidade uma competência essencial no contexto comunicativo do ensino da língua inglesa, faz-se necessário refletir sobre o trabalho e os resultados alcançados por alunos e professores nessa perspectiva no espaço da instituição de ensino regular, oferecendo aos alunos oportunidades reais de contato com a língua "seja lendo, ouvindo, falando, escrevendo, ou interagindo pelo computador" (PAIVA, 2005, p. 140).

De acordo com Richards e Rodgers (1999), o surgimento da abordagem comunicativa se dá também devido a mudanças no cenário educacional europeu. Com a crescente interdependência entre países desse continente, veio a necessidade de esforços maiores para ensinar a adultos as línguas mais importantes do Mercado Comum Europeu e, ainda, da criação do Conselho da Europa. Já no contexto brasileiro, 
conforme Abrahão (2015), a abordagem comunicativa surge nos anos 80, trazida por professores e pesquisadores brasileiros que buscavam sua formação no exterior, justamente devido à escassez de programas de pós-graduação em linguística aplicada no país.

Almeida Filho, um dos pioneiros no uso dessa abordagem de ensino de línguas (EL) no Brasil, narra:

[...] em 1978 voltávamos ao Brasil, depois de um programa de estudos pós-graduados em Linguística Aplicada na Inglaterra, Carmen Rosa Caldas-Coulthard e eu. Ambos sentíamos o peso dos ventos de mudança que sopravam céleres na Europa do então Mercado Comum em construção nas questões educacionais e no âmbito do EL em particular para nós. Na Escócia e Inglaterra mais precisamente em Edimburgo e em Manchester, tínhamos atravessado o tufão filosófico das propostas comunicativas dos meados dos anos 70 e agora estávamos de volta a Florianópolis e São Paulo para enfrentar o sonho de mudança e atualização em terra pátria (ALMEIDA FILHO, 2001, p. 15-16).

Em termos de teoria da língua, a abordagem comunicativa parte da ideia de língua como comunicação. Algo ainda de suma importância para os professores de línguas estrangeiras é que, no momento em que mais uma vez se vivem dúvidas em relação às abordagens, é imprescindível que se tenha um bom conhecimento acerca das bases teóricas destas.

$\mathrm{Na}$ abordagem comunicativa, consideramos que a pronúncia inteligível seja um dos elementos que possibilitam a comunicação. Essa compreensão respeita o âmbito da interfonologia do aluno, desobrigando-o à uma aproximação/imitação de um sotaque nativo. É necessário que a pronúncia leve às unidades de significação que se quer enunciar nos contextos específicos da interação entre os sujeitos falantes. A inteligibilidade é uma condição essencial à construção da interação sociolinguística (BARBOSA, 2011; CRUZ, 2014).

Para além do ensino comunicativo de línguas, a problemática sobre o ensino de língua estrangeira em turmas numerosas é, sem dúvida, algo recente para muitos profissionais de ensino no Brasil. Contudo, as consequências dessa condição, há muito tempo, fazem parte do cotidiano de alunos e professores, particularmente nas instituições públicas no nível da Educação Básica.

Shamim et al. (2007) reforçam que o número de alunos em sala de aula, unicamente, não é suficiente para definir se uma turma pode ser considerada 
numerosa. Conforme os autores, uma turma numerosa, no contexto ocidental, tal como os Estados Unidos ou o Reino Unido, pode ser considerada pequena por professores e alunos, na grande maioria dos casos, se comparada ao ensinoaprendizagem nos contextos africanos, por exemplo. Uma turma numerosa pode variar de 22 alunos no ensino fundamental norte-americano até 150 alunos em uma sala de aula na África.

De acordo com Loo (2007), a ocorrência das turmas numerosas modernas, quase em âmbito mundial, é uma realidade com a qual nem os professores, nem os estudantes, nem as instituições estão felizes. Para a autora, as atividades voltadas para o desenvolvimento da competência comunicativa em turmas numerosas são possíveis, contanto que, para isso, sejam observadas as condições necessárias para viabilizar o trabalho de ensino-aprendizagem significativo.

Fazem-se necessárias estratégias para dar conta das lacunas presentes no ensino de línguas estrangeiras na escola pública, tendo em vista a importante missão em função das grandes demandas educacionais que se avizinham. $\mathrm{O}$ trabalho em dupla ou em grupo, entre outras possibilidades, proporciona oportunidades para o professor orientar os alunos de forma mais eficiente e encontrar disponibilidade para atender os alunos, sem perder a atenção da turma. Em cada grupo, por exemplo, o professor pode orientar 3 ou 4 alunos de uma só vez, o que o ajuda a poupar tempo e energia para atender a outros grupos e acompanhar o desenvolvimento das atividades. Tendo isso em mente, na nossa próxima seção apresentamos o contexto de nossa intervenção pedagógica e a proposta de ensino de que fizemos uso.

\section{Contexto da intervenção pedagógica}

O ensino de língua inglesa nos cursos técnicos de nível médio integrado do IFRN tem, na PTDEM de Língua Inglesa, os princípios que regem o trabalho com a disciplina na instituição. Aprovado pela Resolução n. 38/2012-CONSUP/IFRN, de 26 de março de 2012, o documento se constitui como um referencial organizador da disciplina de língua inglesa, configurando-se como um planejamento macro institucional para a implementação e o desenvolvimento curricular da disciplina nos cursos técnicos de nível médio. A PTDEM de língua inglesa não representa uma imposição, mas, sim, orienta o desenvolvimento do trabalho com a disciplina. 
Embora livre do aspecto impositivo, a proposta para o ensino de língua inglesa constitui um ponto de apoio de relevância significativa para o trabalho docente na instituição, uma vez que sugere uma postura, observando as determinações legais, indicando uma forma de trabalho condizente com a realidade atual e em consonância com as demandas sociais e de mercado, como também com o perfil do aluno da instituição. Levando em consideração esse contexto, elaboramos uma proposta de ensino-aprendizagem do gênero oral entrevista de emprego em língua inglesa no Curso Técnico de Nível Médio em Informática IFRN, com foco, sobretudo, na pronúncia inteligível dos nossos alunos (SILVA, 2018). A Tabela 1, a seguir, sintetiza seus principais elementos, sendo composta pelos dados oficiais do contexto da intervenção e pelas escolhas pedagógicas.

Tabela 1 - Proposta de ensino-aprendizagem da entrevista de emprego em inglês em curso técnico

\begin{tabular}{l|l}
\hline \multicolumn{1}{c|}{ DADOS OFICIAIS } & ESCOLHAS PEDAGÓGICAS \\
\hline Instituto Federal do Rio Grande do Norte, campus Mossoró & Intervenção pedagógica (30h/a) \\
Curso Técnico de Nível Médio Integrado em Informática & Gênero oral entrevista de emprego em \\
Inglês I (90h) & inglês \\
Abordagem comunicativa (PTDEM) & Pronúncia inteligível \\
& Gramática contextualizada \\
& Instruções em inglês \\
& Atividades em duplas \\
& Atividades em grupo \\
\hline
\end{tabular}

Fonte: Silva (2018, p. 68-70, adaptado).

A proposta de ensino-aprendizagem foi realizada através de uma intervenção pedagógica (DAMIANI, 2012; DAMIANI et al., 2013). Nossa intervenção pedagógica foi planejada em 10 encontros, totalizando 30h/a, o equivalente a 1 bimestre letivo de aula. $\mathrm{O}$ bimestre letivo é composto por 10 semanas com 1 encontro semanal de $3 \mathrm{~h} / \mathrm{a}$ da disciplina Inglês I, e nossa h/a corresponde a 45 minutos. O relato dessa experiência pode ser contemplado na narrativa da próxima seção.

\section{Relato da experiência}

Nosso relato de experiência está narrado de modo a sintetizar a realização dos 10 encontros em que colocamos em prática nossa proposta de ensino da entrevista de emprego em inglês, salientando as principais atividades desenvolvidas. Em nosso primeiro encontro, fizemos a apresentação do plano de curso e as observações sobre a 
proposta pedagógica, assim como os desafios em relação ao trabalho com foco na oralidade, em uma turma com elevado número de alunos. Em seguida, demos início ao trabalho com o conteúdo. As questões (em inglês) foram realizadas entre professor e alunos. Depois, passaram a ser realizados entre os alunos, em duplas. Os alunos leram com o professor, repetiram e fizeram exercícios entre si. Em seguida, fizeram a atividade de compreensão oral, na qual eles ouviam nomes estrangeiros sendo soletrados e escreviam os referidos nomes. Durante o desenvolvimento da aula, várias palavras e frases foram escritas no quadro, pronunciadas e escritas pelos alunos em seus cadernos. Essas palavras e frases surgiam durante a interação com os alunos e frequentemente eram usadas em outros contextos durante a aula. A ideia é que, aos poucos, os alunos passem a usar o vocabulário aprendido, diminuindo o uso da língua portuguesa em sala de aula.

Nosso segundo encontro iniciou com o convite de alunos voluntários para um jogo sobre vocabulário da língua inglesa. $\mathrm{O}$ jogo começou com o professor escrevendo a primeira palavra no quadro e, logo em seguida, um aluno escrevia outra palavra, abaixo da palavra do professor, começando com a última letra da palavra escrita anteriormente. Imediatamente, outro aluno escrevia uma nova palavra iniciando com a última letra da palavra escrita pelo primeiro aluno e sucessivamente. O conteúdo da aula foi desenvolvido, buscando-se a interação na língua-alvo. Após a explanação e a interação entre professor e aluno, foram desenvolvidas atividades em duplas e, em seguida, em pequenos grupos. Após as atividades orais em grupos, usando informações de personagens apresentadas no material impresso, os alunos passaram a realizar atividades, fazendo uso de suas próprias identidades. Várias palavras foram listadas para uma ênfase na pronúncia ao final da atividade. O momento foi aproveitado para falar sobre a importância da pronúncia inteligível. O ponto gramatical também foi desenvolvido procurando interagir ao máximo na língua-alvo. Ao final da aula, foi passada uma tarefa para casa: cada aluno deveria pesquisar 25 perguntas em inglês, comuns nas entrevistas deemprego.

Em nosso terceiro encontro, os alunos foram organizados em grupos, variando entre 5 e 6 componentes, para trabalhar com as perguntas da atividade de pesquisa realizada como tarefa de casa. Diante das perguntas pesquisadas por cada aluno, os membros de cada grupo selecionaram as 25 perguntas que acharam mais frequentes e 
interessantes no âmbito do gênero oral entrevista de emprego. Os grupos organizaram as respostas para essas perguntas selecionadas, e cada grupo organizou e realizou uma atividade em dupla, entre os seus membros, com as perguntas e respostas organizadas por eles, a fim de desenvolver e aperfeiçoar seus conhecimentos e competências no gênero escolhido, assim como a pronúncia inteligível das frases. Nesses grupos, os alunos atuaram como entrevistador e entrevistado, fazendo uso das perguntas pesquisadas e selecionadas, com base no roteiro montado com as informações construídas em seus próprios grupos.

O quarto encontro se realizou dando continuidade ao encontro anterior, com perguntas feitas, em princípio, aos alunos com maior proficiência em inglês e, aos poucos, com os que apresentavam menos proficiência. À medida que os alunos iam se envolvendo, passavam a fazer as perguntas entre eles e introduzindo outras perguntas, grafadas no quadro pelo professor ou desenvolvidas pelo próprio aluno.

Em nosso quinto encontro, os alunos fizeram uma atividade de gramática utilizando as formas do simple past, observando imagens para organizar a sequência de uma história. Para dar continuidade à atividade que envolvia uma narrativa, os alunos receberam informações fictícias (nome, idade, endereço, profissão, etc.), assumindo novas identidades. Em duplas e, posteriormente, em grupos, assumiam essas identidades e passavam a pedir e fornecer informações pessoais a seus colegas.

No sexto encontro, houve atividades de leitura e produção escrita dos alunos. Cada aluno produziu o seu profile. Continuando o trabalho com a entrevista de emprego, exploramos o vídeo intitulado job interviews. O vídeo apresentava áudio em inglês e legendas também em inglês. O material, com duração de 35 minutos, foi obtido online na rede social Youtube. Por meio da ferramenta film maker, o vídeo foi subdivido para possibilitar a compreensão e a análise da fala de cada personagem. Foram formuladas várias perguntas orais diretas para os alunos sobre as personagens. Os alunos respondiam oralmente em inglês, propiciando uma interação na língua-alvo entre alunos e professor.

Em nosso sétimo encontro, demos continuidade à atividade do encontro anterior. Os alunos receberam o script das conversações apresentadas no vídeo para tirar dúvidas sobre pronúncia, significados e desenvolvimento de atividades orais. Ao final dessa atividade, alguns pares fizeram apresentações para a turma. 
O desenvolvimento do oitavo encontro se deu através da realização do trabalho com preposições devido à importância na construção de frases frequentes no cotidiano. No nono encontro, foi desenvolvida uma atividade com o título Shadows - What are their Jobs?.Cada aluno recebeu uma folha, contendo 10 figuras numeradas, de sombras de pessoas trabalhando. Em grupos ou duplas, cada aluno escolhia um amigo, dizia o número de uma sombra e perguntava qual era a profissão expressa na figura. Toda a atividade foi desenvolvida procurando usar ao máximo a língua inglesa. Houve a apresentação do vídeo, de aproximadamente 45 minutos, da série Top notch travel agency, em inglês, no qual as personagens se envolvem em várias situações no ambiente de trabalho. Após a apresentação, os alunos responderam a algumas perguntas orais em inglês, feitas pelo professor e, em seguida, responderam a uma atividade com base na compreensão das situações. Foi realizada uma revisão das principais perguntas e respostas, além de palavras mais comuns usadas nas atividades referentes ao gênero entrevista de emprego. Foi feita a organização para a atividade final, na qual os alunos usariam os conhecimentos adquiridos em inglês e sobre o gênero trabalhado ao longo da intervenção. Para a ação final, cada aluno deveria passar pelos papéis de entrevistador e entrevistado, no contexto de uma entrevista de trabalho, na língua-alvo.

No décimo encontro, em pares determinados pelo professor, os alunos atuaram nas situações de entrevistador e entrevistado, fazendo e respondendo perguntas em inglês, conforme as falas de seus interlocutores. Cada aluno, como entrevistador, decidia que perguntas pretendia fazer ao candidato a emprego, papel desempenhado por outro aluno, na condição de entrevistado. Em virtude do grande número de alunos, foi estabelecido que o tempo máximo para cada interação seria de cinco minutos. Em suas entrevistas, os alunos podiam fazer uso das perguntas trabalhadas no questionário e, livremente, inserir novas/outras questões, conforme o contexto da entrevista pedisse. Não houve padronização de pares por nível exclusivo de fluência na língua-alvo. A sequência seguida foi a da ordem de chamada da turma, o que, justamente, permitiu que houvesse diálogos entre alunos que estudavam em cursos privados; entre alunos que frequentavam cursos privados e alunos que não frequentavam cursos privados; e, também, diálogos somente entre alunos que não frequentavam cursos privados. Vale salientar que a decisão de sequenciar a atividade pela ordem de chamada não foi divulgada para os alunos, justamente para evitar alguma possibilidade de combinação de 
perguntas e respostas. E sequência era alterada discretamente, quando o aluno a ser chamado, por alguma razão, não se encontrava no grupo de espera. Chamava-se, então, o nome do aluno seguinte. Devido à quantidade de alunos, não foi possível concluir a atividade no mesmo dia, ficando os alunos restantes para concluí-la no dia seguinte.

Apesar do número de alunos em sala de aula e dos níveis variados de proficiência em relação à língua inglesa, as aulas durante a intervenção pedagógica para o ensino do gênero oral entrevista de emprego em inglês foram muito produtivas, contando com a participação e a atenção de todos. Procuramos seguir as orientações dos documentos norteadores do ensino praticados na instituição, aproveitando-se de suas flexibilidades e lacunas para o desenvolvimento de uma proposta complementar. Devido aos diferentes níveis de proficiência dos alunos na língua-alvo, como já esperado, não foi possível conduzir a aula totalmente em inglês, resultando, na análise do professor, aproximadamente $50 \%$ de uso da língua estrangeira em sala de aula. Para além das atividades com foco exclusivo no ensino da entrevista de emprego em inglês, houve complementação com exercícios rápidos, jogos ou mini-lições que tinham como finalidade, além de uma revisão de gramática e vocabulário, o uso e pronúncia das expressões utilizadas. Por fim, foi possível flagrar várias situações em que as palavras pronunciadas pelos alunos desviavam-se da pronúncia inteligível. Sempre que possível, elas eram anotadas para a realização de um feedback corretivo no final daaula.

\section{Considerações finais}

A estruturação da proposta de ensino-aprendizagem da entrevista de emprego em inglês se mostrou uma eficiente ferramenta na organização e na orientação da intervenção pedagógica que quisemos realizar, pois pudemos observar que houve condições de promover um trabalho muito proveitoso com um gênero oral muito pertinente às necessidades dos nossos alunos do curso técnico de nível médio. Quanto ao ensino comunicativo voltado para a produção oral em língua estrangeira, foi possível o trabalho com a pronúncia na turma numerosa em questão. Foi possível desenvolver o gênero oral, seguindo a proposta comunicativa, realizando trabalhos em duplas e em grupos, habilitando o aluno, independentemente do seu nível de proficiência na língua inglesa, a interagir, fazendo uso do conteúdo desenvolvido em sala de aula. 
Reconhecemos que nosso escopo foi restrito a uma única turma do Curso Técnico de Nível Médio em Informática na região do Oeste Potiguar. Assim, temos ciência de que a intervenção pedagógica com nossa proposta de ensino pode resultar em narrativas distintas, caso a mesma proposta seja aplicada em outra turma do mesmo curso, ou de um curso técnico diferente. A distinção pode vir a ser ainda maior se pensarmos em outras regiões do estado, isto é, outros campi, ou mesmo em outras instituições da Rede Federal de Educação Profissional e Tecnológica do país.

De qualquer forma, acreditamos na flexibilidade dessa proposta de ensinoaprendizagem. Ela não deve ser interpretada como um instrumento normativo, mas pode cumprir a função de nortear o trabalho de outros professores que atuam na Educação Básica da escola pública. A narrativa mostra algumas possibilidades. Cabe ao professor refletir sobre a proposta, os documentos norteadores do ensino em sua própria instituição e fazer as adaptações necessárias para dar continuidade às intervenções pedagógicas que geram dados para a otimização do ensino-aprendizagem de línguas estrangeiras, reportando suas experiências e multiplicando seus saberes.

\section{Referências}

ABRAHÃO, M. H. V. Algumas reflexões sobre a abordagem comunicativa, o pósmétodo e a prática docente. Revista Entre Línguas, Araraquara, v. 1, n. 1, p. 25-42, jan./jun., 2015.

ALMEIDA FILHO, J. C. P. de. O ensino de línguas no Brasil de 1978. E agora? Revista Brasileira de Linguística Aplicada, Belo Horizonte, v. 1, n. 1, p. 15-30, 2001.

BARBOSA, J. R. A. Nem britânico, nem americano: o ensino da pronúncia do inglês como língua internacional. Revista de Letras, Fortaleza, v. 1, n. 30, 2011.

CRUZ, N. C. Inteligibilidade e o ensino da pronúncia do inglês para brasileiros. In.: BRAWERMAN-ALBINI, A.; GOMES, M. L. C. O jeitinho brasileiro de falar inglês: pesquisas sobre a pronúncia do inglês por falantes brasileiros. Campinas: Pontes Editores, 2014. p. 239-252.

DAMIANI, M. F. et al. Discutindo pesquisas do tipo intervenção pedagógica. Cadernos de Educação, Pelotas, n. 45, p. 57-67, maio/agosto 2013.

DAMIANI, M. F. Sobre pesquisas do tipo intervenção - painel: as pesquisas do tipo intervenção e sua importância para a produção de teoria educacional. In: XVI ENCONTRO NACIONAL DE DIDÁTICA E PRÁTICA DE ENSINO, 2012, CAMPINAS. Anais do XVI Encontro Nacional de Didática e Prática de Ensino. Campinas: UNICAMP, 2012. p. 2882-2890. 
LEFFA, V. J. Metodologia do ensino de línguas. In: BOHN, H. I.; VANDRESEN, P. Tópicos em linguística aplicada: o ensino de línguas estrangeira. Florianópolis: UFSC, 1988. p. 211- 236.

LOO, A. Teaching and Learning Modern Language in Large Classes. Berlin: Shaker Ver- lag, 2007.

PAIVA, V. L. M. O. Como se aprende uma língua estrangeira? In: ANASTÁCIO, E. B. A.; MALHEIROS, M. R. T. L.; FIGLIOLINI, M. C. R. (Org.). Tendências contemporâneas em Letras. Campo Grande: Editora da UNIDERP, 2005. p. 127-140.

RICHARDS, J. C.; RODGERS, T. S. Approaches and Methods in Language Teaching. Cambridge: Cambridge University Press, 1999.

SHAMIM, F. et al. Maximizing Learning in Large Classes: Issues and Options. Addis Abbaba: The British Council, 2007.

SILVA, G. M. O ensino de inglês em turmas numerosas: uma proposta de ensino da pronúncia em cursos técnicos de nível médio do Instituto Federal do Rio Grande do Norte. 2018. Dissertação (Mestrado em Ensino) - Instituto Federal de Educação, Ciência e Tecnologia do Rio Grande do Norte, Universidade do Estado do Rio Grande do Norte, Universidade Federal Rural do Semi-Árido, Mossoró, RN, 2018. 